First publ. in: International Journal of Plant Sciences 171 (2010), 4, pp. 382-391, DOI: 10.1086/651226

382

\title{
DOES SPECIALIZED POLLINATION IMPEDE PLANT INVASIONS?
}

\author{
James G. Rodger, ${ }^{1, *}$ Mark van Kleunen, ${ }^{*} \dagger$ and Steven D. Johnson* \\ *Department of Science and Technology National Research Foundation Centre for Invasion Biology, School of \\ Biological and Conservation Sciences, University of KwaZulu Natal, Pietermaritzburg, 3209 South Africa; \\ and tInstitute of Plant Sciences, University of Bern, Altenbergrain 21, CH 3013 Bern, Switzerland
}

\begin{abstract}
Generalized pollination systems and autonomous self fertilization are traits that have been linked with plant invasiveness. However, whether specialized pollination requirements pose a significant barrier to plant invasions is not yet clear. Likewise, the contribution of pollinators to the fecundity of facultatively self pollinating invasive plant species is poorly understood. We addressed these issues using the self compatible and autonomously self pollinating Lilium formosanum, which also has large, showy flowers that are adapted for pollination by hawk moths. We investigated the pollination of this lily which is indigenous to Taiwan in KwaZulu Natal, South Africa, where it is invasive. The long tongued hawk moth Agrius convolvuli was identified as the primary pollinator on the basis of field observations, pollen load analysis, presence of lepidopteran scales on stigmas, and higher seed production in emasculated flowers exposed at night than in those exposed during the day. Remarkably, this moth is native to much of the Old World, including Taiwan and South Africa. Autonomous self pollination resulted in seed production, but at a reduced level relative to the seed production of open and hand pollinated flowers, which was significant in one out of two populations examined. Thus, pollinators potentially contribute to invasion by increasing seed production and genetic variability through cross pollination, although contributions of pollinators to seed set versus that of auton omous self pollination may vary between populations. We conclude that specialized pollination requirements do not present a barrier to invasions when plants are specialized to pollinators or pollinator functional groups with very wide distributions.
\end{abstract}

Keywords: Baker's law, breeding system, biological invasion, prediction, reproductive assurance, sphingophily.

Online enhancement: appendix.

\section{Introduction}

Plants with generalized pollination systems are hypothesized to be more invasive than pollination specialists (Baker 1965, 1974; Richardson et al. 2000), because highly specialized spe cies are unlikely to encounter their particular pollinators in novel environments whereas plants with generalized require ments should be able to utilize alternative pollinators in most environments (Goulson and Derwent 2004; Stout et al. 2006; but see Valentine 1977). Specialization could inhibit invasion if adaptations for pollination by particular pollinator func tional groups or species (evolutionary specialization; Armbrus ter 2006) actually prevent other potential flower visitors from visiting or effectively pollinating. Such evolutionary special ization then results in functionally specialized pollination systems where plants are served by few functional groups and/or ecologically specialized systems, involving few pollinator species (Ollerton et al. 2007). These three types of specializa tion are not always associated with one another (Ollerton et al. 2007). Plants that have specialized pollination systems may invade novel regions if the pollinator taxon or functional

\footnotetext{
${ }^{1}$ Author for correspondence; e mail: rodgerjg@gmail.com.
}

class pollinating them in their native range occurs naturally or has also been introduced in the novel range (Liu and Pemberton 2009), if they switch pollinators (Valentine 1977), or if they can reproduce autonomously. We need more information on the pol lination of invasive species in their introduced ranges to assess the degree to which pollination specialization is a barrier to inva sion in plants (Richardson et al. 2000).

The existence of certain widespread pollination syndromes and corresponding pollinator functional groups (sensu Fenster et al. 2004) suggests that such specialization to a functional class may less frequently impede plant invasions than might be supposed from Baker's $(1965,1974)$ simplistic interpretation of pollinator species and functional groups with quite re stricted distributions. For example, there is a group of mostly self incompatible red flowered plants in the Western Cape province of South Africa that comprise a pollination guild and that show convergent adaptation for pollination by the butter fly Aeropetes tulbagheae, which is restricted to rocky moun taintops and gorges in South Africa and Zimbabwe and which is the exclusive pollinator of these plants (Johnson and Bond 1994). No species in this guild is known to be invasive. On the other hand, the carrion fly pollinated and self incompatible Stapelia gigantea from South Africa sets abundant seed in Venezuela, where it is invasive, as a result of pollination by native carrion flies (Muscidae, Calliphoridae, Sarcophagidae; 
Herrera and Nassar 2009). Several invasive plant species with other specialized pollination syndromes are also visited by members of the same pollinator functional groups in both their native and their introduced ranges (Forster 1994; van Kleunen and Johnson 2005; Geerts and Pauw 2009; Herrera and Nassar 2009). Moreover, if plants with specialized polli nation systems have evolved selfing to cope with vulnerability to fluctuation in pollinator populations (Fenster and Marten Rodriguez 2007; Perez et al. 2009), then this may also consti tute a preadaptation for invasion.

Baker $(1955,1967)$ proposed that autonomous self pollination would promote colonization after long distance dispersal. Recent studies have supported his prediction of a high frequency of self compatible taxa among invasive plants (Rambuda and Johnson 2004; van Kleunen and John son 2007; van Kleunen et al. 2008; but see Sutherland 2004). Autonomous self pollination therefore seems likely to be an important mechanism of reproductive assurance for invasive plants. When pollinators and mates are available, however, self pollination can decrease parental fitness because selfed progeny generally have lower viability and vigor than do out crossed progeny (Husband and Schemske 1996). Pollinators potentially contribute to invasiveness, even in plants that self pollinate autonomously, by increasing the quality and genetic variability of progeny through outcrossing and by increasing quantity of seed produced if autonomous self pollination does not result in fertilization of all ovules (Aizen and Harder 2007). Of the autonomously self pollinating inva sive species studied, pollinators increased seed set in Nicotiana glauca (Geerts and Pauw 2009), Opuntia stricta, Carpobrotus acinaciformis (Bartomeus and Vila 2009), and Crotalaria retusa (Jacobi et al. 2005), but not in Muntingia calabura (de Fi gueiredo et al. 2008). Pollinators may thus promote invasion, even in autonomously self pollinating plant species.

The invasive geophyte Lilium formosanum is self compatible and autogamous (Inagaki 2002; Rambuda and Johnson 2004). Flowers conform to the hawk moth pollination syn drome (Vogel 1954; Waser 2006), and the plant is reputed to be pollinated by hawk moths in its introduced range in Japan (H. Inagaki, personal communication), although to the best of our knowledge its pollination has not been studied in the native range in Taiwan. Lilium formosanum is therefore a very promising candidate for investigating the relevance of pollination specialization for invasion and the importance of animal pollinators versus autonomous self pollination. Agrius convolvuli, the most common large hawk moth in the South African invasive range of L. formosanum, is also indig enous in Japan and Australia (Pittaway and Kitching 2007). A very similar congener, Agrius cingulatus, occurs in the southern United States (Opler et al. 2006), where L. formo sanum is also invasive. That transcontinental plant invasion might be facilitated not merely by pollinators of the same functional type as those in the plant's native range but by the very same species is remarkable.

In this study we investigated the degree of specialization of the pollination system of L. formosanum in its invaded range in KwaZulu Natal, South Africa, and the potential for animal pollinators versus autonomous self pollination to contribute to fecundity. Specifically, we asked the following questions: (1) Does this plant experience effective biotic polli nation, and if so, by which pollinating agents? And (2) can pollinators potentially increase fecundity over that which is achieved by autonomous self pollination alone (i.e., is seed set pollen limited under purely autonomous self pollination)?

\section{Materials and Methods}

\section{Study Species}

Lilium formosanum Wallace (Liliaceae) is native to Taiwan but has become invasive in the moist eastern parts of South Africa (Henderson 2001) and Australia (AVH 2007), in the southern United States (USDA 2007), and in the southern is lands of Japan (Inagaki 2002). It is a geophyte that produces annual aboveground parts during summer and, in South Africa, that flowers between January and April (May). In South Africa it invades anthropogenically disturbed habitats such as road verges and plantation edges; it also invades natural grassland and may therefore pose a threat to native plant species. Stems are unbranched, $0.32 .5 \mathrm{~m}$ tall, with a terminal candelabra like inflorescence of one to eight flowers (fig. 1). The flowers are white, trumpet shaped, and strongly scented at night, with nectar borne near the base of the flower, far from the sexual parts. Nectar volume (mean $\pm \mathrm{SE}, 47.0 \pm 7.3 \mu \mathrm{L} ; n=10$ ), sugar concentration $(36.1 \% \pm 2.0 \% ; n=10)$, and anther and stigma height $(122.5 \pm 2.9 \mathrm{~mm}$ and $140.5 \pm 2.9 \mathrm{~mm}$, respec tively; $n=22$ ) as measured in a population of Lilium formosa num near Hilton (lat. $26^{\circ} 30.528^{\prime} \mathrm{S}$, long. $30^{\circ} 17.216^{\prime} \mathrm{E}$ ) are consistent with flowers pollinated by Agrius hawk moths in South Africa and elsewhere (Alexandersson and Johnson 2002; Martins and Johnson 2007). Individual flowers abscise $47 \mathrm{~d}$ after anthesis (median $=6 \mathrm{~d}$; J. G. Rodger, unpublished re sults). Capsules take $\sim 10$ wk to mature and contain a few hundred to over 1000 flat, dry, winged seeds.

Controlled pollination experiments have shown that the species is self compatible and autonomously self pollinating in its introduced ranges but that it does not display nonpseu dogamous apomixis (Inagaki 2002; Rambuda and Johnson 2004). A trend for lower seed set with autonomous self pollination than with hand pollination (Rambuda and Johnson 2004) suggests that pollinators may contribute to fecundity. A molecular marker study indicated that the species has a mixed mating system in Taiwan, its native range (Hiramatsu et al. 2001). The stigma usually projects beyond the anthers, and the anthers normally dehisce on the day of anthesis. Self pollination is effected by pollen falling or being shaken by the wind off the anthers and onto the stigma, at times by contact between stigmas and anthers in flowers, and during perianth abscission when anthers are often dragged across the stigma (Inagaki 2002; J. G. Rodger, personal observa tion), although stigma receptivity is low at perianth abscis sion (J. G. Rodger, unpublished results).

\section{Study Sites}

All populations examined were located in the invasive range in the KwaZulu Natal Midlands and coastal regions (between lat. $29^{\circ} 25^{\prime}$ and $30^{\circ} 55^{\prime} \mathrm{S}$ and between long. $30^{\circ} 05^{\prime}$ and $30^{\circ} 50^{\prime} \mathrm{E}$, and from 0 to $1500 \mathrm{~m}$ a.s.l.). They were lo cated either in disturbed grassland adjacent to exotic tree 

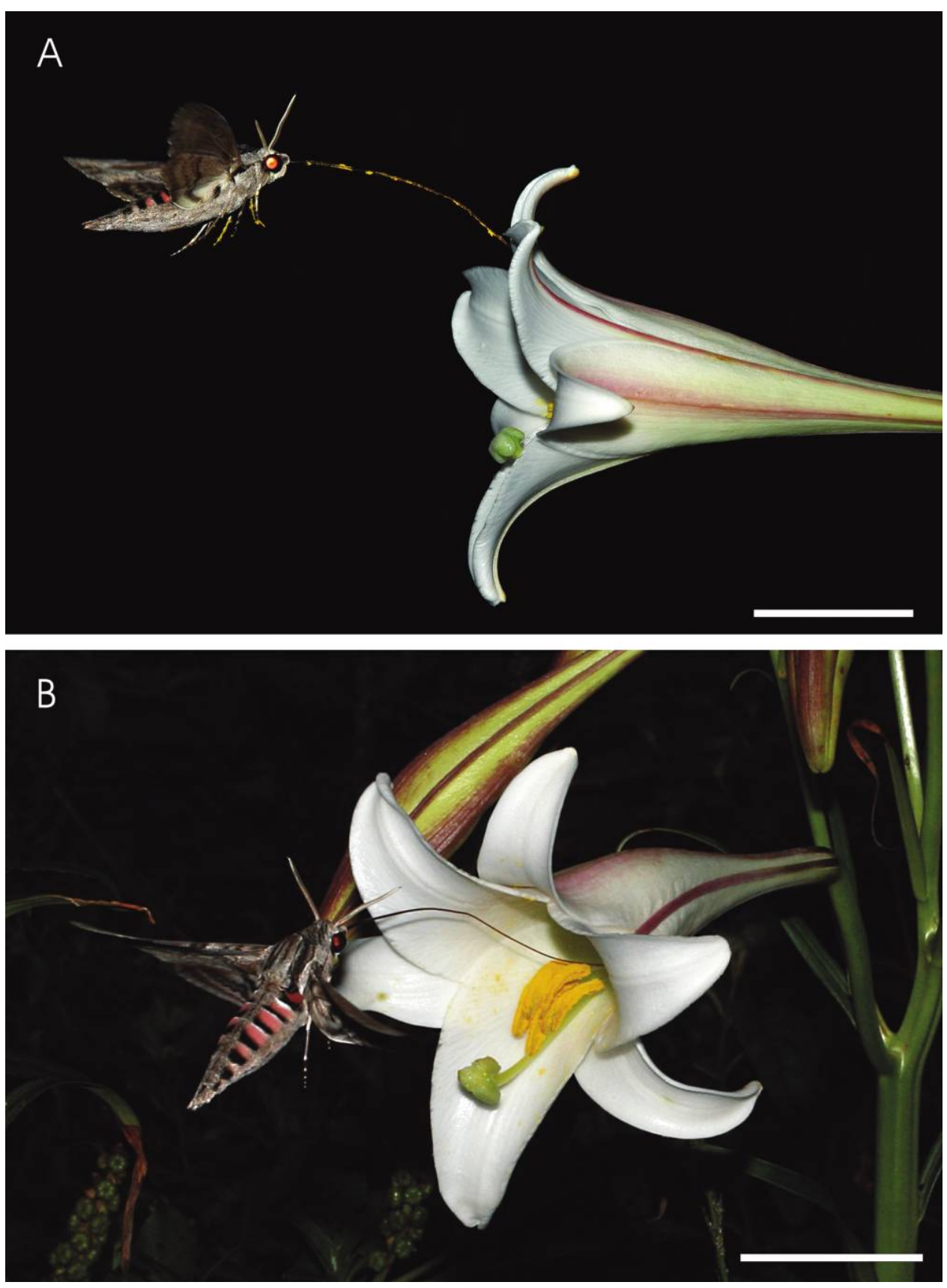

Fig. 1 Agrius convolvuli visiting the flowers of Lilium formosanum. A, Side view of a flower approached by a hawk moth carrying pollen on its proboscis and legs. (Photograph by S. D. Johnson.) B, Front view of a flower showing the position of the anthers and stigma, which will contact the underside of the approaching moth's body. Scale bar $30 \mathrm{~mm}$. (Photograph by C. Botes.)

plantations and invaded by Rubus cuneifolius or in grassy road verges. For logistical reasons, different experiments were not all performed at the same sites; details of sites used are provided in each case.

\section{Visitor Observations and Pollen Loads}

Relative abundances of nocturnal visitor species were as sessed in 20 nocturnal observation sessions performed in the KwaZulu Natal Midlands between January and March of
2006 and 2007. In 2006, nine observation sessions were per formed in disturbed grassland at Wahroonga Farm (lat. $29^{\circ} 36.598^{\prime} \mathrm{S}$, long. $30^{\circ} 07.990^{\prime} \mathrm{E} ; 1350 \mathrm{~m}$ a.s.l.) and four were performed in disturbed grassland at Cedara (lat. $29^{\circ} 31.904^{\prime}$ S, long. $30^{\circ} 16.117^{\prime} \mathrm{E} ; 1042 \mathrm{~m}$ a.s.1.). In 2007, three sessions were performed at Wahroonga Farm and four were performed in grassland alongside a road in the Karkloof (lat. $29^{\circ} 20.190^{\prime} \mathrm{S}$, long. $30^{\circ} 16.669^{\prime} \mathrm{E} ; 1096 \mathrm{~m}$ a.s.l.). One to three observers watched as many flowers as possible for $\sim 1$ $h$, beginning just after sunset. Visitation normally decreased 
in frequency toward the end of the observation period. The number of flowers visited and the identity and behavior of all visitors were recorded.

In addition to direct observations of moths, we indirectly as sessed moth visitation in 2007 by examining flowers in 27 populations for the presence of lepidopteran scales. These pop ulations were located in the KwaZulu Natal Midlands and the coastal regions (lat. $29^{\circ} 25^{\prime} 30^{\circ} 55^{\prime} \mathrm{S}$, long. $30^{\circ} 05^{\prime} 30^{\circ} 50^{\prime} \mathrm{E}$ ). Scale inspections were conducted for a median of 19 randomly chosen flowers per population: 1824 flowers per population were inspected, except where there were fewer than 18 flowers per population, in which case all of the flowers were inspected, and for two populations in which 60 and 48 flowers were in spected, respectively. Stigmas and perianths were examined with the aid of a $\times 20$ magnifying hand lens. Although scales are not always deposited during visitation (J. G. Rodger, per sonal observation), scale deposition is likely to be correlated with visitation. A $\chi^{2}$ test was used to test for variation be tween populations in scale deposition for the 19 populations in which 18 or more flowers were inspected.

Abundance of diurnal visitors was assessed by inspecting up to 20 flowers in each of 24 populations (a total of 415 flowers) during 2007 (a subset of those scored for scale depo sition). Inspections were performed between 0900 and 1600 hours. The number of individuals of each species of visitor was scored in each flower at the moment it was inspected. This snapshot method was used because virtually all diurnal visitors we observed spent long periods of time in individual flowers. In a period of over $70 \mathrm{~d}$ in the field that was spread across $5 \mathrm{yr}$ of work on L. formosanum flowers, we have ob served only four honeybees (Apis mellifera) and one bee of another species visiting the flowers. Three of the A. mellifera individuals foraged for pollen, one robbed nectar by inserting its proboscis through the tepals, and none were observed contacting the stigma. The one non Apis bee observed on the flower was not observed to forage. No other fast moving di urnal visitors were observed.

Visitors were captured for identification and to quantify their pollen loads. Fuchsin stained gelatin was used to re move pollen from their bodies (Kearnes and Inouye 1993). The abundances of both Lilium and other pollen grains were counted under a compound microscope at $\times 100$ magnifica tion (there was no other species of Lilium flowering in the vicinity of study populations). Agrius convolvuli individuals were daubed on the head, the mouthparts, and the ventral part of the body, as these were the parts observed to contact anthers and that sometimes carried visible pollen loads. Other species were daubed all over the body. Pollen purity was calculated for each individual as the number of $L$. for mosanum pollen grains divided by the total number of pollen grains. For the most abundant nocturnal and diurnal visitor species (A. convolvuli and the cetonid beetle Cyrtothyrea marginalis, respectively), log pollen loads were compared us ing $t$ tests and pollen purity was compared using Mann Whitney $U$ tests.

\section{Day Night Pollinator Exclusion Experiment}

The relative importance of diurnal and nocturnal visitors for fertilization was investigated in two populations, Wah roonga and Cedara (see above), in February 2006. Flowers were emasculated and exposed to pollinators either during the day ( $n=11$ at Wahroonga and $n=8$ at Cedara) or at night ( $n=11$ at Wahroonga and $n=7$ at Cedara). Flowers were emasculated before anthesis to prevent self pollination and were covered with nylon mesh bags to exclude visitors. Only a single flower was treated on any particular individ ual plant. From anthesis onward, flowers were exposed to visitors by removing and replacing bags just after sunset and just after sunrise, as appropriate. Treatments were per formed over five consecutive days in each population. Emas culation potentially affects visitation by removing the pollen reward and by changing the appearance of the flowers. Moth visitation is unlikely to be affected by emasculation, however, as they do not forage for pollen; indeed, moths ap peared to visit emasculated flowers as readily as nonemascu lated flowers.

Fruits were harvested at maturity, fruit set was scored, and seed set per flower was estimated. Seeds were counted as such if they contained an embryo that was at least half the length of the seed, excluding the wing. Where flowers set fruit, number of seeds was estimated by first calculating mean number of seeds per milligram in two samples of 50 seeds and unfilled ovules from each fruit and then by multi plying this value by the total seed mass for each fruit.

Fruit set (a binomially distributed variable) for nocturnally and diurnally accessible flowers were compared using boot strapping for the two populations separately. In each pop ulation, fruit set for replicates of each treatment was bootstrapped, with replacement from fruit set values of the two treatments combined 1000 times. The difference in the proportion of flowers that set fruit between nocturnal pollina tion and diurnal pollination was calculated for the original data and for each bootstrap randomization. We present $P$ values as the proportion of randomizations in which the differ ence in fruit set proportion for the two treatments in the boot strapped data sets was greater than or equal to that observed for the actual data (two tailed). This estimates the probability of obtaining a difference between the treatments by chance that is as great or greater than that actually observed.

Number of seeds per fruit (for flowers that formed fruit) was compared between treatments using a $t$ test assuming equal variances (the significance level did not change when a $t$ test for unequal variances was used). This was performed for the Cedara population only, as there was no fruit set for the diurnally exposed treatment at Wahroonga.

\section{Breeding System}

Lilium formosanum is known to be self compatible, and it self pollinates autonomously (Inagaki 2002; Rambuda and Johnson 2004), but a trend for higher fecundity with hand pollination than with autonomous self pollination (Rambuda and Johnson 2004) suggests that seed set is pollen limited un der autonomous self pollination. Therefore, to test whether animal pollinators increase seed set, we conducted further controlled pollination experiments in two populations.

The two populations used were a freeway verge pop ulation adjacent to the Mariannhill Toll Plaza on the N3 between Pietermaritzburg and Durban (lat. 29 49.415'S, 
long. $30^{\circ} 48.014^{\prime} \mathrm{E} ; 395 \mathrm{~m}$ a.s.l.) and a disturbed grassland

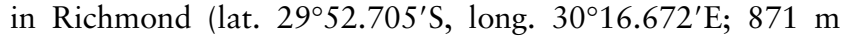
a.s.l.); these were observed in January and February 2006. Flowers were assigned randomly to one of five treatments: four of these were bagged with nylon mesh bags before an thesis to exclude visitors, and the fifth was left open to polli nators (open pollinated) as a control for the effectiveness of hand pollination compared with natural pollination and to test for pollen limitation under open pollination. Only one flower was treated on any single plant. In two of the treat ments, $12 \mathrm{~d}$ after anthesis, flowers were either self pollinated or cross pollinated with pollen from a plant located at least $2 \mathrm{~m}$ away in order to test for self compatibility. Cross pollinated flowers were emasculated at the time of bagging to prevent self pollination. In the bagged control treatment, flowers were left unmanipulated in bags to test for autono mous self pollination. In another treatment, bagged flowers were emasculated before anthesis and left unpollinated to test for the possibility of nonpseudogamous apomixis. Ten flowers were used per treatment per population, except where 20 flowers were used for open pollination at Mariann hill and 15 were used for the bagged control treatment at Richmond. Number of seeds per flower was measured (as de scribed for the day night pollinator exclusion experiment) to evaluate differences among treatments.

The effects of treatment and population on fruit set were examined by bootstrapping as in the day night pollinator ex clusion experiment, but several comparisons were made in each treatment to test separate hypotheses (Resampling Stats 2009). Tests were performed separately for each population. Hand self and cross pollination treatments were compared to test for self compatibility. Because very similar fruit set levels occurred in these two treatments, their data were pooled for remaining contrasts. To test for autonomous self pollination, the bagged control was compared with hand pollination. Open pollination was compared with hand polli nation to test for the effectiveness of hand pollination and for pollen limitation. To test whether pollinators increased fruit and seed set above levels achieved by autonomous selfing, we compared open pollination with the bagged control treat ment. Because there was no fruit set whatsoever in the emascu lated flowers, no statistical comparison with any other treatment was performed. Numbers of seeds per fruit (for flowers that set fruit) were compared using $t$ tests for the same set of comparisons detailed above, except for those involving the emasculation treatment, where no fruits were set, and for the bagged control treatment at Mariannhill, which resulted in only three fruits. We used $t$ tests for equal variances (signifi cance levels did not change when a $t$ test for unequal variances was used). For flowers that set fruit, seed to ovule ratios were also calculated and cross and self pollination were compared with $t$ tests to test for early acting inbreeding depression.

An index of self compatibility was calculated as the ratio of mean number of seeds per flower for self pollination to mean number of seeds per flower for cross pollination (Ken rick and Knox 1989) for each population. Similarly, an index of autonomous self pollination was calculated as the ratio of mean number of seeds per flower in the bagged control treat ment to mean number of seeds per flower for self pollination (see Eckert et al. 2006).

\section{Statistical Software}

All statistical analyses were conducted in SPSS 15 (SPSS 2008), except for bootstrapping, for which the Poptools add in for Microsoft Excel was used (Hood 2009).

\section{Results}

\section{Visitor Observations}

Agrius convolvuli (Sphingidae), a long tongued hawk moth, was by far the most abundant nocturnal visitor. Indi viduals were observed in 2006 during three out of four obser vation sessions at Cedara and five out of nine at Wharoonga, and in 2007 during zero out of three sessions at Wharoonga and one out of four at Karkloof. During all nocturnal obser vations, a total of 28 individual insects were observed, of which 27 were $A$. convolvuli. The one other individual was an unidentified large, nonsphingid moth species. Agrius con volvuli was responsible for 155 of the 156 observed visits to flowers. Agrius convolvuli individuals hovered while inserting their very long (mean $\pm \mathrm{SE}, 101.2 \pm 6.3 \mathrm{~mm} ; n=7$ ) tongues into the perianth tube, and they settled very briefly onto the anthers, making contact with the stigma, before leaving the flower (fig. 1). Visits typically lasted a few seconds; where more than one flower was open on the same plant, the flowers were often visited sequentially. Substantial pollen deposits were observed on previously virgin emasculated flowers after visitation by $A$. convolvuli, demonstrating effec tive cross pollination (J. G. Rodger, personal observation). Although many nonsphingid moths were active at the sites, except for the single exception mentioned above, they did not visit Lilium formosanum.

Lepidopteran scales conforming to those of A. convolvuli were found on flowers in 22 out of 27 populations. Scales were generally deposited on the stigma or on perianth lobes near the entrance to the flower. In only one case was a dense deposit of scales observed deep down in the perianth tube, below the level where the body of $A$. convolvuli could have fit. This indicates that smaller, shorter tongued moths do oc casionally visit L. formosanum. In the 19 populations for which 18 or more flowers were inspected, a range of $0 \%$ $68.4 \%$ of flowers had scales (mean $\pm \mathrm{SE}, 25.3 \% \pm 5.0 \%$ ). Frequency of scale deposition varied significantly between these $\left(\chi_{18}^{2}=52.24, P<0.001\right)$, suggesting that pollinator visitation varies between populations.

Cyrtothyrea marginalis (Scarabaeidae, Cetoniinae) was the only diurnal visitor found in more than one population that also had a mean pollen load of more than one L. formosa num pollen grain (see tables A1 and A2 in the online edition of International Journal of Plant Sciences). They were pres ent in 15 out of 24 populations inspected, with $0.241 \pm 0.049$ (mean \pm SE) beetles per flower (averaged across popula tions). These beetles fed on the anthers or forced themselves deep down into the perianth tubes to get to the nectar. They were observed to contact the stigma, which they sometimes used as a launch pad for taking off. Other common visitors were minute beetles, flies, aphids, and thrips. These insects carried extremely low pollen loads and are very sedentary (J. G. Rodger, personal observation), and so they could con tribute only negligibly to pollination. Information regarding 
number of populations in which each species of visitor was observed, abundance, and pollen loads is contained in tables $\mathrm{A} 1$ and $\mathrm{A} 2$.

Lilium formosanum pollen loads on A. convolvuli were an order of magnitude greater $\left(t_{35}=3.65, P<0.001\right)$ than were those on Cyrtothyrea marginalis $\left(45.8 \pm 17.9, t_{35}=3.65\right.$, $P<0.001)$. Pollen purity of $A$. convolvuli was $0.89 \pm 0.05$ $(n=7)$, and that of C. marginalis was $0.66 \pm 0.07(n=30)$, but there was no significant difference between the two spe cies $(z=1.090 \mathrm{~m}, P=0.138$; see tables A1 and A2). Re sults of statistical comparisons were qualitatively identical when other Cetoniinae were pooled with C. marginalis.

\section{Day Night Pollinator Exclusion Experiment}

Emasculated flowers that were accessible to pollinators during the night had significantly higher fruit sets than did those accessible during the day at Wahroonga $(P<0.001)$ but not at Cedara $(P=0.152)$. However, fruit from noctur nal pollination at Cedara contained significantly more seeds than did fruit from diurnal pollination $\left(t_{8}=7.189 ; P<0.001\right.$; fig. 2b).

\section{Breeding System}

Fruit set proportion and mean number of seeds per fruit are shown in figure $3 A$ and $3 B$, and $P$ values for comparisons between treatments are presented in table 1 . Fruit set and seed set were very similar between cross and self pollination treatments at both Richmond and Mariannhill, indicating com plete self compatibility. Values for these two hand pollination treatments were therefore pooled for comparison with other treatments in further comparisons. No fruit were produced in bagged emasculated flowers in either population, indicat ing an absence of nonpseudogamous apomixis. Fruit set was similar between the hand pollination and the open pollina tion groups, and seed set was higher under hand pollination, although this was significant only at Mariannhill. This shows that the hand pollination technique was adequate in both populations and that seed set was pollen limited at Mariann hill. Fruit set was lower under autonomous self pollination (bagged control treatment) than under hand pollination, but it was significantly so only at Mariannhill, demonstrating that seed set is pollen limited under autonomous self pollina tion for that population. Similarly, autonomous self pollina tion resulted in lower fruit set than did open pollination, but this was significant only at Mariannhill, indicating that polli nators contributed to seed set there.

Seed to ovule ratios (means $\pm \mathrm{SE}$ ) at Richmond were $0.56 \pm$ 0.06 for cross pollination, $0.64 \pm 0.07$ for self pollination, $0.53 \pm 0.05$ for bagged control, and $0.52 \pm 0.07$ for open pol lination, and at Mariannhill they were $0.72 \pm 0.04$ for cross pollination, $0.84 \pm 0.03$ for self pollination, $0.83 \pm 0.07$ for bagged control, and $0.63 \pm 0.07$ for open pollination. There was a slightly higher seed to ovule ratio in cross pollination versus self pollination at Mariannhill $\left(t_{15}=2.143, P=0.050\right)$ but not at Richmond $\left(t_{14}=0.782, P=0.446\right)$, suggesting in breeding depression during early seed development in the for mer population.
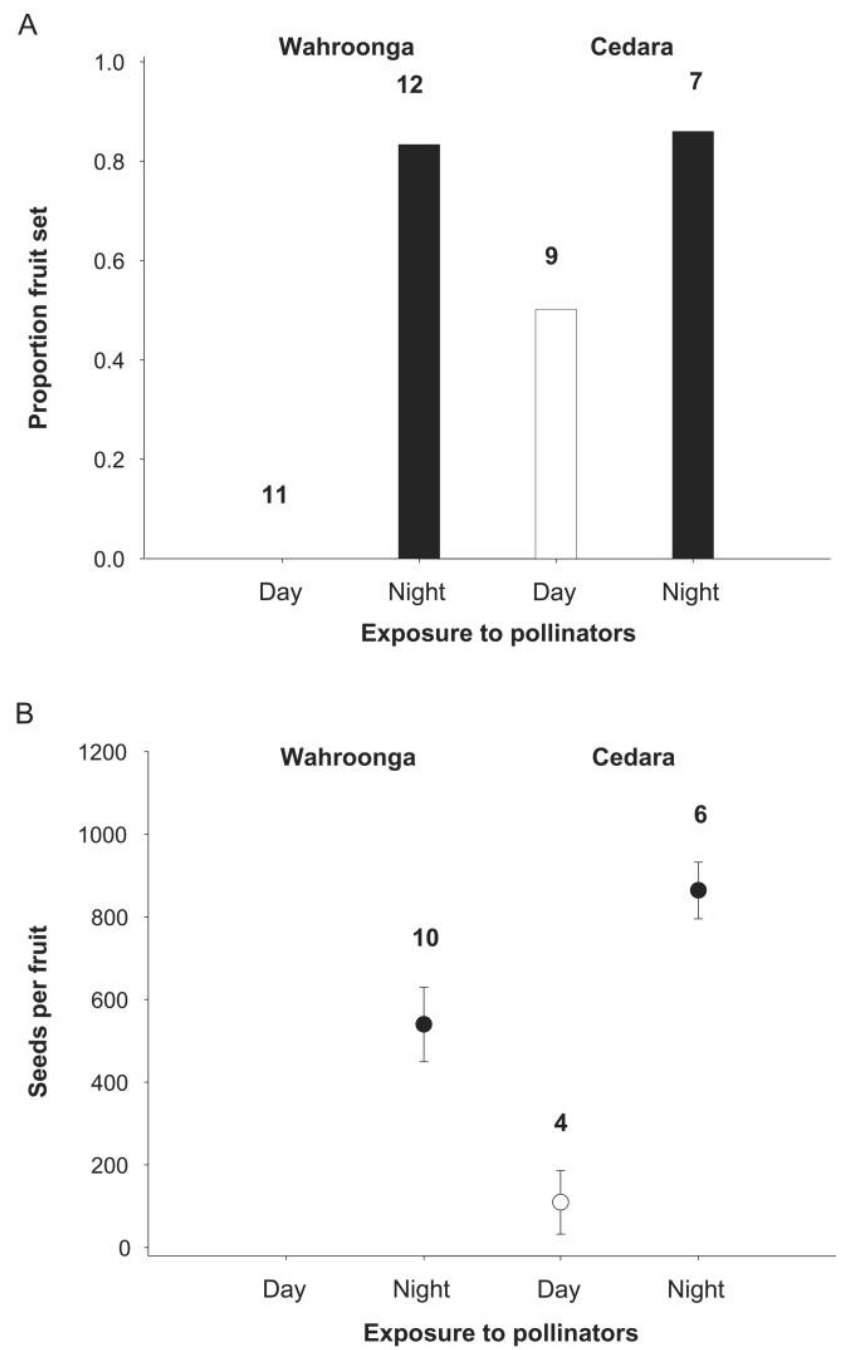

Fig. 2 Proportion fruit set $(A)$ and number of seeds per fruit (mean $\pm \mathrm{SE} ; B)$ in a day night pollinator exclusion experiment in two populations of Lilium formosanum. Numbers above bars are sample sizes.

Indices of autonomous self pollination were 0.54 for Rich mond and 0.30 for Mariannhill. Indices of self compatibility of 1.17 at Richmond and 1.04 at Mariannhill show complete self compatibility.

\section{Discussion}

Our field observations and experiments show that the hawk moth Agrius convolvuli, which is also indigenous in the native range of Lilium formosanum in Taiwan, is the primary pollina tor of L. formosanum in its invasive range in KwaZulu Natal, South Africa. Lilium formosanum thus displays high levels of both functional and ecological specialization (Armbruster 2006; Ollerton et al. 2007) in South Africa. Agrius convolvuli potentially contributes to invasion in L. formosanum by in creasing seed set, as autonomous self pollination results in the fertilization of significantly fewer ovules than do open and hand pollinations in one of the two populations studied here 


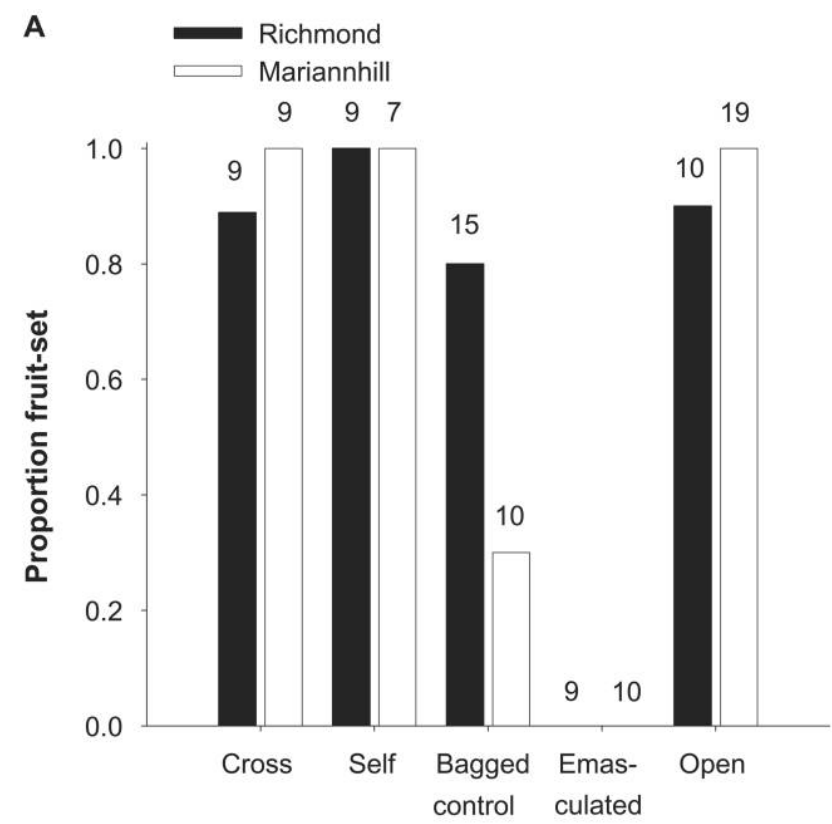

B

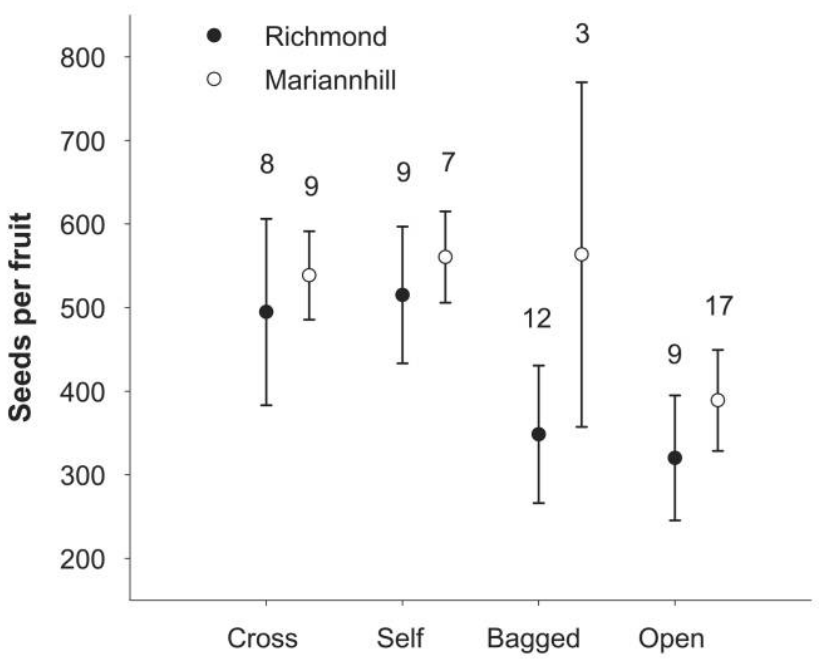

Fig. 3 Proportion fruit set $(A)$ and number of seeds per fruit (mean \pm $\mathrm{SE} ; B)$ in a breeding system experiment in two populations of Lilium formosanum. Numbers above bars are sample sizes.

(table 1; fig. 3). Relative importance of pollinators versus autonomous self pollination may vary between populations, however. Nevertheless, specialized pollination requirements are not a barrier to invasion when plants are adapted to widespread pollinators.

All evidence indicates that $A$. convolvuli is the primary pol linator of L. formosanum in the study region. Nocturnal visi tors were shown to be highly effective pollinators, while diurnal visitation resulted in very low or no seed production (fig. 2). Agrius convolvuli was far and away the most abun dant nocturnal pollinator observed in these populations (table A1). The finding of lepidopteran scales on flowers in the ma jority of the investigated populations across the distribution range in KwaZulu Natal is also consistent with A. convolvuli being the main pollinator. These scales were also found on $L$. formosanum flowers on Long Tom Pass in Mpumalanga (a neighboring province of KwaZulu Natal), South Africa (lat. $25^{\circ} 8.480^{\prime}$ S, long. 30³7.266'E; $2000 \mathrm{~m}$ a.s.l.; S. Morita and M. Profitt, personal observations). Variation in scale deposi tion among populations suggests that different populations dif fer markedly in terms of visitation. While there are many other sphingid species in the study area, only one much rarer species, Coelonia mauritii, has a tongue that is as long as that of $A$. convolvuli. Other species are probably not able to reach the nectar because of the length of the flower tube.

Although one diurnal species, the fruit chafer beetle Cyrto thyrea marginalis, was found in many KwaZulu Natal popula tions, it carried an order of magnitude less L. formosanum pollen than $\operatorname{did} A$. convolvuli (tables A1 and A2), and as such it probably makes a minor contribution to cross pollination when the hawk moths are absent or rare. All other visitors were either too rare or carried too little pollen to contribute meaningfully to pollination.

The breeding system experiment showed that, at least in some populations, pollinators contribute to fecundity of $L$. formosanum in South Africa, as there was significantly lower reproductive success under autonomous self pollination than under open pollination and hand pollination in one of the two populations studied (fig. 3; table 1). This is due to insuffi cient self pollen grains being transferred autonomously, as L. formosanum is completely self compatible (fig. 3; table 1; Inagaki 2002; Rambuda and Johnson 2004). An earlier study in South Africa (Rambuda and Johnson 2004) and the other population in this study showed nonsignificant trends for lower reproductive success under autonomous self pollination versus open pollination, and there was also no difference between seed set for these treatments in Japan (Inagaki 2002). It appears, at least in South Africa, that populations vary in their capacity for autogamy.

The seed to ovule ratio at Mariannhill was higher under cross pollination than under self pollination, probably as a re sult of inbreeding depression during early seed development; however, this did not affect number of seeds per fruit, which suggests compensation for inbreeding depression by high ovule number (Porcher and Lande 2005). Moreover, no in breeding depression was detected in terms of seed mass, seed abortion, proportion germination, and survival up to $6 \mathrm{mo}$, which suggests that progeny produced by selfing, whether autonomous or pollinator mediated, contribute to parental fitness and potentially to invasion (J. G. Rodger, M. van Kleunen, and S. D. Johnson, unpublished results).

Hawk moth pollination probably comprises a combination of facilitated within flower self pollination, geitonogamy, and cross pollination. It is likely that autonomous self pollination contributes to invasion in L. formosanum by providing repro ductive assurance when pollinators are scarce or absent, and when A. convolvuli is abundant, it contributes to invasion by increasing seed set above the levels achieved by autonomous self pollination alone. Outcrossing mediated by these pollina tors may also result in increased genetic variation and favor able new gene combinations, enhancing local adaptation. As capacity for autogamy and visitation (using scale deposition as an index) appears to vary between populations (fig. 3; Rambuda and Johnson 2004), so too may the relative importance of polli nators and autonomous self pollination. 
Table 1

Statistical Comparison of Fruit Set and Number of Seeds per Fruit for Different Treatments in Breeding System Experiments Conducted at Richmond (R) and Mariannhill (M)

\begin{tabular}{|c|c|c|c|c|}
\hline \multirow[b]{2}{*}{ Hypothesis tested, treatments compared, population } & \multirow[b]{2}{*}{ Fruit set $P$} & \multicolumn{3}{|c|}{ Seeds per fruit } \\
\hline & & $t$ & $\mathrm{df}$ & $P$ \\
\hline \multicolumn{5}{|l|}{ Self compatibility hypothesis: } \\
\hline \multicolumn{5}{|l|}{ Cross pollination versus self pollination: } \\
\hline $\mathrm{R}$ & .116 & .15 & 15 & .883 \\
\hline M & a & .29 & 14 & .779 \\
\hline \multicolumn{5}{|l|}{$\begin{array}{l}\text { Pollen limitation, hand pollination technique: } \\
\text { Hand pollination }{ }^{\text {b }} \text { versus open pollination: }\end{array}$} \\
\hline $\mathrm{R}$ & .29 & 1.75 & 24 & .93 \\
\hline M & a & 2.15 & 33 & .039 \\
\hline \multicolumn{5}{|l|}{ Autonomous self pollination: } \\
\hline \multicolumn{5}{|l|}{ Hand pollination versus bagged control: } \\
\hline $\mathrm{R}$ & .209 & 1.50 & 27 & .144 \\
\hline M & $<.001$ & c & & \\
\hline \multicolumn{5}{|l|}{ Contribution of pollinators to seed set: } \\
\hline \multicolumn{5}{|l|}{ Open pollination versus bagged control: } \\
\hline $\mathrm{R}$ & .101 & .245 & 19 & .809 \\
\hline M & $<.001$ & c & & \\
\hline
\end{tabular}

a Test omitted because all flowers in both treatments set fruit.

$\mathrm{b}$ "Hand pollination" refers to the pooled hand self and cross pollination treatments.

${ }^{c}$ Test omitted because sample size was three for the bagged control group.

We were unable to establish when selfing occurs relative to outcrossing, although stigma receptivity is reduced at perianth abscission. Because stigmas are receptive and pollen is released on the first day of anthesis, it is likely that self pollination occurs, possibly incurring a cost of reduced out crossing and a potential for local adaptation (J. G. Rodger, M. van Kleunen, and S. D. Johnson, unpublished results).

Recent studies indicate that a number of invasive species displaying functionally specialized pollination systems in their native ranges are adapted to pollinators that belong to wide spread functional groups (sensu Fenster et al. 2004), which potentially facilitates their invasion. In another autonomously self pollinating invader, Nicotiana glauca, which is adapted to hummingbird pollination in Argentina, pollination by na tive sunbirds in South Africa also increases seed production above levels achieved by autonomous selfing (Geerts and Pauw 2009; see also Schueller 2004). The carrion fly pollinated Stapelia gigantea (Herrera and Nassar 2009) and the vespid wasp pollinated Gomphocarpus physocarpus (Coombs et al. 2009; Forster 1994), which are both pollinator dependent, have also reestablished their pollination systems after trans continental invasion. Senna didymobotrya is self compatible, but it requires buzz pollination by large bees. It is pollinated by Xylocopa flavorufa in its invaded range in South Africa (van Kleunen and Johnson 2005), by Xylocopa pubescens in horticulture in Israel (Dulberger 1981), and presumably by $X$. flavorufa and other Xylocopa species in its native range in tropical Africa. Thus, the potential role of pollinators in pro moting invasion should not be ignored, even in autono mously self pollinating, self compatible plants.

The pollination of $L$. formosanum has not, to the best of our knowledge, been studied in its native range. While we cannot exclude the possibility that other pollinator functional groups contribute to pollination there, it seems unlikely that they are important. Many pollinator functional groups occur ring in Taiwan also occur in South Africa, and they were not observed to visit L. formosanum. Most nectar feeders are probably excluded by the inaccessibility of the nectar. Al though pollen is readily accessible, bees were almost never observed on the flowers (see "Materials and Methods"), sug gesting that L. formosanum pollen is unattractive to them.

There is a guild of plants in southern Africa (e.g., Gladio lus longicollis, Crinum delagoense) with similar floral mor phologies and scents that represents an apparent convergent evolution for pollination by Agrius convolvuli and the much rarer hawk moth Coelonia mauritii (Alexandersson and Johnson 2002; Martins and Johnson 2007; S. D. Johnson and R. A. Raguso, unpublished research). Lilium formosa num may threaten some of these plants by competing for pol linators. However, L. formosanum flowers mainly from January to March, and most of the native plants in the guild finish flowering around the end of January. There may even be an indirect facilitative effect if the presence of L. formosanum results in higher abundance of $A$. convolvuli (S. D. Johnson and R. A. Raguso, unpublished research).

Aside from A. convolvuli (Pittaway and Kitching 2007), we are not aware of any species of pollinator for which plants have become evolutionarily specialized (Armbruster 2006) and that is naturally so widespread. Generally, plants adapted to a particular functional group will be pollinated by different members of that functional group in their native and introduced ranges. Although $A$. convolvuli belongs to a fairly narrow pollinator functional group of hawk moths with tongue length on the order of $10 \mathrm{~cm}$ (Haber and Frankie 1989; Agosta and Janzen 2005), it was the only member of this group that was observed in this study. Agrius convolvuli occurs over the entire native and invaded ranges of $L$. formo sanum except in North America, where a morphologically similar congener, Agrius cingulatus, occurs (Opler et al. 2006). In our study area, $A$. convolvuli also visits the invasive 
Ipomoea alba, which is native to the tropical and subtropical parts of the New World, and Hedychium gardenarianum, which comes from northern India (S. D. Johnson and R. A. Ra guso, unpublished research). The broad geographical range of Agrius hawk moths, particularly A. convolvuli, means that there is much potential for them to facilitate the invasion of plant spe cies moved from one part of their range to another.

The hypothesis that plants with specialized pollination re quirements will be unlikely to find pollinators when intro duced to novel environments (Baker 1965, 1974) does not take into account that pollinator functional groups and even particular pollinator species may be very widespread. Study ing examples involving specialization to pollinators as diverse as carrion flies, vespid wasps, hawk moths, and nectar feeding birds allows us to refine the original prediction: specialized pollination requirements should be an impediment to plant invasion to the extent that the pollinator species or func tional group (Fenster et al. 2004) involved is restricted in its geographic distribution.

\section{Acknowledgments}

This research was funded by the National Research Foun dation and the Department of Science and Technology through the Centre of Excellence for Invasion Biology in Stellenbosch. Thanks to Ezemvelo KwaZulu Natal Wildlife for permission to collect insects, to the Kunhards for allow ing us to work on Wahroonga, to Lawrence Harder for ad vice on statistical analysis, to Ray Miller for identifying the Scatopsid flies, to Shelah Morita and Magali Profitt for scale observations on Long Tom Pass, to Kyoko Yamamura for translating parts of the Japanese manuscript by H. Inagaki, to Dalton Nyawo for assistance with seed counting, to Christo Botes for photography, and to Stefan Dötterl, Jessy Tupholme, and Vanessa Pasqualetto for assistance with polli nator observations. This manuscript was improved by com ments from Jeff Ollerton and five anonymous reviewers, two of whom commented on a previous version of this manu script.

\section{Literature Cited}

Agosta SJ, DH Janzen 2005 Body size distributions of large Costa Rican dry forest moths and the underlying relationship between plant and pollinator morphology. Oikos 108:183 193.

Aizen MA, LD Harder 2007 Expanding the limits of the pollen limitation concept: effects of pollen quantity and quality. Ecology 88:271 281.

Alexandersson R, SD Johnson 2002 Pollinator mediated selection on flower tube length in a hawkmoth pollinated Gladiolus (Iridaceae). Proc R Soc B 269:631 636.

Armbruster WS 2006 Evolutionary and ecological perspectives on specialization: from the Arctic to the tropics. Pages 260282 in NM Waser, J Ollerton, eds. Plant pollinator interactions: from specialization to generalization. University of Chicago Press, Chicago.

AVH 2007 Australia's Virtual Herbarium. http://www.rbg.vic.gov .au/avh/. Accessed April 19, 2007.

Baker HG 1955 Self compatibility and establishment after "long distance" dispersal. Evolution 9:347 349.

1965 Characteristics and modes of origin of weeds. Pages 147172 in HG Baker, GL Stebbins, eds. The genetics of colonizing species. Academic Press, New York.

1967 Support for Baker's Law as a rule. Evolution 21: 853856

1974 The evolution of weeds. Annu Rev Ecol Syst 5:1 24.

Bartomeus I, M Vila 2009 Breeding system and pollen limitation in two supergeneralist alien plants invading Mediterranean shrub lands. Aust J Bot 57:109 115 .

Coombs G, CI Peter, SD Johnson 2009 A test for Allee effects in the self incompatible wasp pollinated milkweed Gomphocarpus physo carpus. Aust Ecol 34:688 697.

de Figueiredo RA, AA de Oliveira, MA Zacharias, SM Barbosa, FF Pereira, GN Cazela, JP Viana, RA de Camargo 2008 Reproductive ecology of the invasive exotic tree Muntingia calabura L. (Muntingiaceae) in southeastern Brazil. Rev Arvore 32:993 999.

Dulberger R 1981 The floral biology of Cassia didymobotrya and Cassia auriculata (Caesalpinaceae). Am J Bot 68:1350 1360.

Eckert CG, KE Samis, S Dart 2006 Reproductive assurance and the evolution of uniparental reproduction in flowering plants. Pages 183203 in LD Harder, SCH Barrett, eds. Ecology and evolution of flowers. Oxford University Press, New York.

Fenster CB, WS Armbruster, P Wilson, MR Dudash, JD Thom son 2004 Pollination syndromes and floral specialization. Annu Rev Ecol Evol Syst 35:375 403.

Fenster CB, S Marten Rodriguez 2007 Reproductive assurance and the evolution of pollination specialization. Int J Plant Sci 168: 215228.

Forster PI 1994 Diurnal insects associated with the flowers of Gomphocarpus physocarpus E. Mey (Asclepidaceae), an introduced weed in Australia. Biotropica 26:214 217.

Geerts S, A Pauw 2009 African sunbirds hover to pollinate an invasive hummingbird pollinated plant. Oikos 118:573 579.

Goulson D, LC Derwent 2004 Synergistic interactions between an exotic honeybee and an exotic weed: pollination of Lantana camara in Australia. Weed Res 44:195 202.

Haber WA, GW Frankie 1989 A tropical hawkmoth community: Costa Rican dry forest Sphingidae. Biotropica 21:155 172.

Henderson L 2001 Alien weeds and invasive plants. Agricultural Research Council, Pretoria.

Herrera I, JM Nassar 2009 Reproductive and recruitment traits as indicators of the invasive potential of Kalanchoe daigremontiana (Crassulaceae) and Stapelia gigantea (Apocynaceae) in a Neotropical arid zone. J Arid Env 73:978 986.

Hiramatsu M, K Ii, H Okubo, KL Huang, CW Huang 2001 Bio geography and origin of Lilium longiflorum and L. formosanum (Liliaceae) endemic to the Ryukyu Archipelago and Taiwan as determined by allozyme diversity. Am J Bot 88:1230 1239 .

Hood GM 2009 PopTools. Ver 3.1.1. http://www.cse.csiro.au/poptools.

Husband BC, DW Schemske 1996 Evolution of the magnitude and timing of inbreeding depression in plants. Evolution 50:54 70 .

Inagaki H 2002 Research on self fertilisation in Lilium formosanum Wallace. J Weed Sci Technol 47:147 152.

Jacobi CM, M Ramalho, M Silva 2005 Pollination biology of the exotic rattleweed Crotalaria retusa L. (Fabaceae) in NE Brazil. Biotropica 37:357 363 .

Johnson SD, WJ Bond 1994 Red flowers and butterfly pollination in the fynbos in South Africa. Pages 137148 in M Arianoutsou, RH Groves, eds. Plant animal interactions in Mediterranean type ecosystems. Kluwer Academic, Dordrecht.

Kearnes CA, DW Inouye 1993 Techniques for pollination biologists. University of Colorado Press, Niwot.

Kenrick J, RB Knox 1989 Quantitative analysis of self incompatibility in trees of seven species of Acacia. J Hered 80:240 245. 
Liu H, RW Pemberton 2009 Solitary invasive orchid bee outperforms co occurring native bees to promote fruit set of an invasive Solanum. Oecologia 159:515 525.

Martins DJ, SD Johnson 2007 Hawkmoth pollination of Aerangoid orchids in Kenya, with special reference to nectar sugar concentra tion gradients in the floral spurs. Am J Bot 94:650 659 .

Ollerton J, A Killick, E Lamborn, S Watts, M Whiston 2007 Multiple meanings and modes: on the many ways to be a generalist flower. Taxon 56:717 728.

Opler PA, H Pavulaan, RE Stanford, M Pogue 2006 Butterflies and moths of North America. Vol 2007. Mountain Prairie Information Node. http://www.butterfliesandmoths.org/species?1 3356. Ac cessed June 15, 2009.

Perez F, MTK Arroyo, JJ Armesto 2009 Evolution of autonomous selfing accompanies increased specialization in the pollination systems of Schizanthus (Solanaceae). Am J Bot 96:1168 1176.

Pittaway IR, IJ Kitching 2007 Sphingidae of the eastern Palaearctic. http://tpittaway.tripod.com/china/a con.htm. Accessed July 5, 2007.

Porcher E, R Lande 2005 Reproductive compensation in the evolution of plant mating systems. New Phytol 166:673 684 .

Rambuda TD, SD Johnson 2004 Breeding systems of invasive alien plants in South Africa: does Baker's rule apply? Divers Distrib 10: 409416.

Resampling Stats 2009 Resampling stats add in for Excel users. Stats, Arlington, VA. http://www.resample.com/content/software/ excel/userguide/RSXLHelp.pdf. Accessed November 30, 2009.

Richardson DM, N Allsopp, CM D'Antonio, SJ Milton, M Rejmánek 2000 Plant invasions: the role of mutualisms. Biol Rev Camb Philos Soc 2000:65 93.

Schueller SK 2004 Self pollination in island and mainland popula tions of the introduced hummingbird pollinated plant, Nicotiana glauca (Solanaceae). Am J Bot 91:672 681.

SPSS 2008 SPSS 15.0 for Windows. SPSS, Chicago.

Stout JC, JAN Parnell, J Arroyo, TP Crowe 2006 Pollination ecology and seed production of Rhododendron ponticum in native and exotic habitats. Biodivers Conserv 15:755 777.

Sutherland S 2004 What makes a weed a weed? life history traits of native and exotic plants in the USA. Oecologia 141:24 39.

USDA 2007 The PLANTS database. Vol 2007. Natural Resources Conservation Service National Plant Data Center, Baton Rouge, LA.

Valentine DH 1977 The pollination of introduced species with special reference to the British Isles and the genus Impatiens. Pages 117123 in AJ Richards, ed. The pollination of flowers by insects. Academic Press, New York.

van Kleunen M, SD Johnson 2005 Testing for ecological and genetic Allee effects in the invasive shrub Senna didymobotrya (Fabaceae). Am J Bot 92:1124 1130.

2007 Effects of self compatibility on the distribution range of invasive European plants in North America. Conserv Biol 21:1537 1544.

van Kleunen M, JC Manning, V Pasqualetto, SD Johnson 2008 Phylogenetically independent associations between autonomous self fertilization and plant invasiveness. Am Nat 171:195 201.

Vogel S 1954 Blutenbiologische Typen als Elemente der Sippenglie derung, dargestellt anhand der Flora Sudafrikas. Bot Stud 1: 1388.

Waser NM 2006 Specialization and generalization in plant pollinator interactions: a historical perspective. Pages 318 in NM Waser, J Ollerton, eds. Plant pollinator interactions: from specialization to generalization. University of Chicago Press, Chicago. 